\title{
LINGUAGEM, TECNOLOGIA E APRENDIZAGEM: A PRÁTICA DISCURSIVA DO HACKER
}

\author{
ALLAN STROTTMANN KERN ${ }^{1}$ \\ Programa de Pós-Graduação em Ciências da Linguagem \\ Universidade do Vale do Sapucaí \\ Av. Pref. Tuany Toledo, 470 - 37550-000 - Pouso Alegre - MG - Brasil \\ allan kern@hotmail.com
}

Resumo. Refletimos aqui sobre como a tecnologia digital e seus dispositivos significam, produzindo efeitos, no e pelo sujeito inscrito no lugar de aprendiz. A partir da análise discursiva do ensaio conhecido como "manifesto hacker", discutimos sobre os sentidos de ensino e aprendizagem nas sociedades capitalistas contemporâneas, onde a produção do conhecimento é regulada pelo Estado através de instituições como a Escola e a Universidade. Procuramos compreender, a partir desse gesto analítico, o conjunto de conhecimentos e técnicas dos hackers como dispositivos de leitura que podem romper com as discursividades dominantes em certos espaços institucionais, sobretudo no que se refere ao que é possível e o que é legitimado (ou não) na produção do conhecimento, tomada aqui como produção de sentido.

Palavras-chave: discurso; tecnologia digital; sujeito; leitura.

\begin{abstract}
Here, we reflect on how digital technology and its devices mean, producing effects, on and by the subject subscribed in the place of learner. From the discursive analysis of the essay known as "the hacker manifest", we discuss the meanings of teaching and learning in contemporary capitalist societies, where the production of knowledge is regulated by the State through institutions such as School and the University. With this analytical gesture, we aim to comprehend the hackers' set of knowledge and techniques as reading devices that may disrupt the dominant discursivities within certain institutional spaces, especially regarding what is possible and legitimized (or not) in the production of knowledge, taken here as production of meaning.
\end{abstract} Keywords: discourse; digital technology; subject; reading.

\footnotetext{
${ }^{1}$ Mestre e doutorando em Ciências da Linguagem pela Universidade do Vale do Sapucaí.
} 
Todo saber fazer é um querer dizer. Jacques Rancière

\section{Introdução}

Este artigo é parte de uma pesquisa ${ }^{2}$ que busca compreender as práticas de hacking como práticas discursivas, de acordo com a perspectiva teórica da análise de discurso de linha materialista. Em nossas primeiras leituras sobre o tema, encontramos um texto escrito em 1986, conhecido como "o manifesto hacker". Sobretudo, ficamos intrigados com a afirmação do autor de que a sua história como hacker havia começado na escola. Ele se descreve como um aluno incompreendido, com um potencial não reconhecido pelos seus professores, e lembra de seu primeiro acesso a um computador como uma experiência que o transformou enquanto sujeito social e sujeito do conhecimento.

A leitura desse texto nos levou a pensar mais especificamente sobre o modo como o acesso às redes de computadores transforma as relações de produção do conhecimento, que, nas formações sociais capitalistas, são legitimadas em (e por) instituições tais como as escolas e universidades. Assim, nos detivemos no fato de que as práticas pedagógicas escolares são centralizadas no e pelo professor (aquele com a função de "ensinar"), enquanto os modos de aprendizagem baseados no acesso às "redes" prescindem de uma figura de autoridade ocupando essa posição.

A partir daí, começamos a nos perguntar sobre os efeitos de sentidos dos termos "ensino" e "aprendizagem", tanto no âmbito das práticas pedagógicas escolares quanto no das práticas de acesso às redes a partir de dispositivos digitais. Como a aprendizagem significa nessas (e através dessas) diferentes práticas? Quais são os efeitos do ensino sobre a aprendizagem, tanto no espaço físico das escolas quanto no espaço virtual das redes? Quais são os efeitos dessas práticas discursivas na constituição do sujeito de linguagem como sujeito do conhecimento? E, tendo em vista que o ponto de partida desta reflexão foi o "manifesto hacker", há outra questão que nos acompanhará ao longo desse percurso: o que as práticas de hacking têm a nos ensinar sobre os processos de produção e circulação do conhecimento nas atuais condições de produção do discurso, estruturadas no e pelo funcionamento da tecnologia digital?

Nossa proposta de endereçar essas questões se fundamenta na perspectiva teórica da análise de discurso de linha materialista, e esta filiação tem implicações importantes uma vez que mobilizamos noções como linguagem, discurso e sujeito. Em primeiro lugar, os fatos de linguagem são pensados face ao funcionamento do discurso e da ideologia, e o sentido tomado não como algo que estaria "contido" nos diferentes objetos simbólicos, mas como um "efeito" produzido em condições que abrangem o sujeito, a enunciação e a história (PÊCHEUX, 1969). Além disso, o sujeito é considerado enquanto "posição", constituída no discurso em uma "forma" historicamente determinada, e em processos de identificação com formações discursivas que organizam as diferentes políticas do dizer (PÊCHEUX, 1975).

\footnotetext{
${ }^{2}$ Trata-se de nossa pesquisa de doutorado, iniciada na Univás em 2017.
} 
A partir dessa perspectiva, buscamos analisar determinados efeitos de sentidos do "manifesto hacker" sobre o engajamento do sujeito aprendiz nas práticas escolares e nas práticas de acesso a redes digitais. A seguir, aprofundamos a discussão sobre a relação entre ensino e aprendizagem nessas diferentes práticas discursivas, tomando os trabalhos de Rancière (1987) e Orlandi (2014) como referência. Por fim, procuramos endereçar a questão da aprendizagem nas atuais condições de produção a partir de uma reflexão sobre efeitos possíveis das novas tecnologias no trabalho da leitura.

\section{O "manifesto hacker"}

O texto que ficou conhecido como o "manifesto hacker" traz o desabafo de um jovem fanático por computadores, que havia sido preso após ser pego navegando em uma rede onde ele "não poderia estar" (BLANKENSHIP, 2002). O texto, assinado pelo hacker "The Mentor" em 8 de janeiro de 1986, foi publicado no mesmo ano no zine eletrônico Phrack ${ }^{4}$, e logo ganhou notoriedade entre hackers e entusiastas em geral da chamada "cibercultura".

Em uma palestra em 2002, o autor do "manifesto" descreve a si mesmo (idem) como um adolescente solitário que havia descoberto, através das redes de computadores, a possibilidade de fazer amizades e trocar diferentes tipos de arquivos (textos, jogos, etc.) com outras pessoas como ele que, em diversos lugares do mundo, tinham acesso à "rede" a partir de um computador e uma linha telefônica. Os computadores ofereciam, a quem soubesse como utilizá-los, a possibilidade de conhecer e de aprender a fazer coisas novas. Novas formas de significar o mundo e de se significar no mundo, que, para este autor, foram interditadas quando ele foi apanhado "onde ele não deveria estar". Daí o sentimento de "ódio" e a "frustração" citados por ele ao relembrar a situação que o motivou a escrever (ibidem).

O texto ${ }^{5}$ começa com a citação de manchetes de jornal sobre o adolescente pego "brincando" nas redes de computadores. A citação é seguida por um comentário irônico: "malditas crianças, são todas iguais".

O fato de que esse texto, escrito como um "desabafo", tenha sido (re)conhecido como um manifesto por uma nova classe de jovens escondidos em suas casas (os "nerds") é significativo, do ponto de vista da sociedade e das (falhas das) suas instituições, quando se observa o modo como o autor se define enquanto hacker:

[...] você já parou para dar uma olhada nos olhos de um hacker? [...]. Eu sou um hacker, conheça o meu mundo... O meu mundo começa na escola... eu sou mais esperto que a maioria das outras crianças, essa porcaria que eles ensinam me entedia....

\footnotetext{
${ }^{3} \mathrm{O}$ título original do texto era The Conscience of a Hacker ("a consciência de um hacker"), mas um dos efeitos de sua circulação foi o de que ficasse conhecido como The Hacker Manifesto.

${ }^{4} C f$. www.phrack.org/.

${ }^{5}$ Para todas as citações diretas do manifesto, ver o Anexo. Optamos por apresentar os trechos traduzidos no corpo do texto para facilitar a leitura.
} 
O comentário irônico aparece aqui novamente, desta vez com um deslizamento: "maldito fracassado ${ }^{6}$, são todos iguais".

O autor então prossegue relatando sua adolescência na escola: "estou no ginásio ou no colegial. Já escutei os professores explicarem pela décima quinta vez como reduzir uma fração. Eu entendo". E se lembra de estar dizendo à professora: "não, senhora Smith, eu não mostrei os cálculos. Eu fiz de cabeça...". E o comentário irônico se repete, novamente em uma paráfrase, porém desta vez com um acréscimo: "maldita criança, provavelmente copiou; são todas iguais".

Os parágrafos seguintes descrevem a descoberta, pelo autor, do que ele podia fazer com um computador. O comentário irônico aparece de novo, com outro deslizamento: "maldita criança, tudo que faz é ficar brincando; são todas iguais".

A partir do que descobre que pode fazer com um computador, o autor descobre também um espaço social: "é a esse lugar que eu pertenço; eu conheço todo mundo aqui, ainda que nunca tenha encontrado ninguém, por mais que nunca tenhamos conversado antes, e por mais que nunca mais conversemos novamente, eu conheço todos vocês". E, mais uma vez, o comentário irônico: "malditas crianças, ocupando o telefone de novo; são todas iguais".

Então, os relatos da infância e adolescência entremeados de comentários irônicos dão lugar ao verdadeiro "desabafo", marcado pela formulação de parágrafos mais longos. Em um deles, as (más) lembranças e impressões da escola voltam a ganhar corpo:

você pode apostar que somos todos iguais... nós fomos alimentados com papinha de bebê quando queríamos comer bife... os pedacinhos de carne que vocês deixaram passar eram pré-digeridos e sem gosto. Fomos dominados por sádicos, ou ignorados pelos apáticos. Os poucos que tinham algo a ensinar encontraram entre nós pupilos dedicados, mas aqueles poucos são como gotas de água no deserto.

Essas formulações chamaram a nossa atenção porque o autor do texto se define, enquanto hacker, a partir de uma contra-identificação com as suas lembranças da escola (especialmente os professores e as atividades em sala de aula). Ou seja, a escola produziu efeitos importantes na constituição desse sujeito, sobretudo, pelo modo como ela falhou com ele, pelo modo como ele recorda a professora rejeitando o seu gesto de interpretação, enfim, pela forma como esse sujeito se viu ali incompreendido.

\section{Das formações imaginárias à posição-sujeito no discurso}

Ao passarmos da leitura do texto para a análise do discurso que nele se materializa, começamos pela observação e interpretação do funcionamento das formações imaginárias (PÊCHEUX, 1969) na formulação. Mais especificamente, nos detivemos nas imagens que o autor faz de si mesmo ("mais esperto que as outras crianças"), de seus professores

\footnotetext{
${ }^{6}$ No inglês: "Damn underachiever".
} 
("sádicos" que dominavam os alunos e/ou "apáticos" que os ignoravam) e da imagem que os professores fazem dele (que aparece na repetição de comentários irônicos).

Nesses três conjuntos de imagens, a relação entre professor e aluno se configura como uma relação marcada pelo equívoco, na medida em que o aluno que se diz "esperto" é tratado como um "fracassado" (underachiever), isto é, alguém que está sempre aquém das expectativas postas pelo professor enquanto sujeito que deve ao mesmo tempo ensinar e regular os efeitos de sentido desse ensino com mecanismos de avaliação. Esse trabalho, como toda tentativa de organizar/fixar/controlar a produção do discurso - entendido como "efeito de sentidos entre locutores" (idem) - é um ritual que está sempre sujeito à falha, no movimento do sujeito, da história, do simbólico.

Observemos com mais cuidado a repetição de comentários irônicos, que mostram, neste caso, o que o aprendiz acha que seus professores pensam dele. A fim de mostrar a relação, que nunca pode ser totalmente exata, entre a nossa tradução e o texto base ${ }^{7}$, optamos por apresentar os comentários também em inglês.

Damn kids. they're all alike. Malditas crianças. São todas iguais.

Damn underachiever. They're all alike. Maldito fracassado. São todos iguais.

Damn kid. Probably copied it. Maldita criança. Provavelmente copiou.

They're all alike São todas iguais.

Damn kid. All he does is play games. Maldita criança. Tudo o que fazé brincar.

They're all alike. São todas iguais.

Damn kid. Tying up the phone line again. Maldita criança. Ocupando a linha de novo.

They're all alike. São todas iguais.

A repetição da formulação "all alike" marca o funcionamento de um discurso que silencia o sujeito-aprendiz, apagando seus gestos de autoria e as práticas simbólicas nas quais ele (se) investe, e que faz tábula rasa do aluno enquanto sujeito do conhecimento. Mais particularmente, a recorrência desse dizer no discurso do sujeito aponta para uma recusa desse "ser igual" ou "parecido" ou "semelhante" às outras crianças/adolescentes, pois ele se considera "mais esperto que a maioria", embora isso não esteja aparente para os seus professores (vistos como "sádicos" ou "apáticos").

Além disso, a repetição dessas formulações marca um efeito de descontinuidade entre os sentidos da prática de ensino-aprendizagem para o professor e para o estudante, para aquele que está na "posição de ensinar" e aquele que está na "posição de aprender". O que aponta para uma disjunção mais geral, entre os sentidos de ensino e aprendizagem

\footnotetext{
${ }^{7}$ Nosso objetivo, ao traduzirmos o texto e falarmos sobre a tradução, não é atingir uma suposta "precisão" do sentido, mas dar visibilidade à sua não-transparência, face à materialidade da(s) língua(s). A expressão "damn kid" poderia ser traduzida para o português como "criança danada", mas optamos pela formulação "maldito(a)(s)" porque esta se aproxima, na fala brasileira, do modo como a palavra inglesa funciona na fala do autor norte-americano. Já a expressão "all alike" não significa "iguais", mas "muito parecidos", "semelhantes". Também aqui, optamos por uma forma que se aproxima da oralidade. No caso, associamos a formulação em inglês "all alike" ao "tudo igual", característico do português brasileiro.
} 
no âmbito das práticas realizadas na e pela escola, enquanto instituição responsável por organizar e administrar a relação dos sujeitos com o conhecimento. Nessas condições, a contra-identificação do autor do manifesto com os sentidos de aprendizagem (im)postos na e pela escola se constitui a partir da inscrição em uma formação discursiva distinta daquela que predomina nas práticas escolares.

Assim, o autor do texto se constitui como posição-sujeito a partir do gesto que desvincula o "ensino" oferecido nas escolas, através dos professores, e a "aprendizagem" resultante do engajamento do aprendiz. Esse aluno não se enreda no discurso do professor, o que faz falhar a prática de ensino, mas isso não significa que não haja aprendizagem. Ela apenas se realiza por outros meios. Nesse sentido, o aluno que não se inscreve nas práticas escolares e encontra outros caminhos para aprender se constitui, no discurso, como um sujeito que resiste aos efeitos dessas práticas.

Segundo Orlandi, (2012, p. 230), a questão da resistência "está, de um lado, vinculada à relação entre forma-sujeito-histórica e a individuação pelo Estado; de outro, pelo processo de identificação do sujeito individuado com a formação discursiva", e é nesse movimento a partir do qual "o sujeito individu(aliz)ado se identifica que pode haver ruptura" (idem). Assim, pensamos que o manifesto é a formulação de um discurso de resistência em relação às pedagogias centradas na atuação do professor. Isto é, ao passo que a escola falha em sua função de mediar a relação desse sujeito de linguagem com as formas de produção do conhecimento (processo de individuação), esse sujeito encontra outras possibilidades de identificação com as formações discursivas que organizam as relações de sentidos ligados aos diferentes campos do saber.

Uma vez que observamos o discurso deste hacker como um discurso de resistência ao modo como a relação com o conhecimento é organizada/administrada na e pela escola, passamos a interrogar os efeitos de sentidos da relação entre ensino e aprendizagem. Como essa relação significa em práticas discursivas distintas, tanto no âmbito das escolas quanto no do acesso às "redes"?

\section{Efeitos de sentidos de ensino e aprendizagem}

Em “O mestre ignorante" (1987), Jacques Rancière conta a história do professor Joseph Jacotot, que, exilado na Holanda em meados do século XIX, viu-se encarregado de ensinar o idioma francês a um grupo de alunos holandeses, sem saber falar o holandês. E conseguiu, sem que fosse preciso passar aos aprendizes qualquer lição convencional. Sua solução foi oferecer-lhes uma edição bilíngue de um livro (o Telêmaco) e deixar que eles aprendessem, a partir da tradução, o texto francês. Segundo Rancière (idem, p. 18), tratava-se de uma "solução de improviso", uma espécie de experimentação que superou todas as expectativas de Jacotot. O fato de que seus alunos holandeses tinham, sozinhos, "buscado as palavras francesas correspondentes àquelas que conheciam, e as razões de suas desinências" (idem, p. 20), e, também sozinhos, "haviam aprendido a combiná-las, para fazer, por sua vez, frases francesas" (idem), levou o professor a repensar tudo o que lhe parecia mais evidente sobre o seu próprio papel nos processos de aprendizagem. 
A revelação que acometeu Jacotot se relaciona ao seguinte: é preciso inverter a lógica do sistema explicador. A explicação não é necessária para socorrer uma incapacidade de compreender. É, ao contrário, essa incapacidade, a ficção estruturante da concepção explicadora de mundo. É o explicador que tem a necessidade do incapaz, e não o contrário, é ele que constitui o incapaz como tal. (ibidem, p. 23)

De acordo com Rancière (idem), o sucesso inesperado do experimento de Jacotot fez com que o professor colocasse em questão a necessidade das explicações providas por um mestre "sábio" ou "conhecedor" para que o aprendiz tivesse as condições de aprender. A concepção de uma tal aprendizagem na qual o sujeito que tem "menos conhecimento" precisa ser guiado por outro com "mais conhecimento" passa a ser criticada por Jacotot, que compreende então o "princípio da explicação" como o princípio do embrutecimento (ibidem, p. 24), uma vez que a suposição da explicação como necessária à aprendizagem tem por efeito submeter a inteligência do aprendiz à inteligência do mestre.

Distinguem-se, assim, duas modalidades de aprendizagem. A que funciona como embrutecimento submete a vontade e a inteligência do aprendiz à vontade e à inteligência do mestre. Já na forma de aprendizagem que funciona como emancipação, a vontade do aprendiz pode até se submeter à vontade do mestre, mas sua inteligência é reconhecida enquanto tal e não precisa se subordinar. Essa compreensão é uma das razões pelas quais a experiência inusitada e bem-sucedida do professor Jacotot produzia "uma ruptura com a lógica de todas as pedagogias" (ibidem, p. 32). Como escreve Rancière, no prefácio à edição brasileira de "O mestre ignorante",

a distância que a Escola e a sociedade pedagogizada pretendem reduzir é aquela de que vivem e que não cessam de reproduzir. Quem estabelece a igualdade como objetivo a ser atingido, a partir da situação de desigualdade, de fato a posterga até o infinito (...). Instruir pode, portanto, significar duas coisas absolutamente opostas: confirmar uma incapacidade pelo próprio ato que pretende reduzi-la ou, inversamente, forçar uma capacidade que se ignora ou se denega a se reconhecer e a desenvolver todas as consequências desse reconhecimento. (RANCIÈRE, 2002, p. 11-12).

Essa formulação tem consequências fortes para a reflexão sobre a aprendizagem, não só porque (d)enuncia a contradição entre o que a escola e o ensino se propõem a fazer e o que de fato fazem, mas também porque mostra o funcionamento do equívoco no modo como é a própria formulação do objetivo pedagógico que põe em xeque a sua realização, na medida em que "cria" o problema que se propõe a "resolver", isto é, supõe uma falta (de conhecimento ou inteligência) que depois tenta suprir.

Orlandi (1988), ao refletir sobre as práticas de leitura, chega a uma conclusão bastante parecida.

[...] em linguagem (e, logo, em leitura) não há grau zero assim como não há grau dez. Na dicotomia entre método de ensino e processo de aprendizagem, a escola se coloca como se o aluno não tivesse já instalado um processo de aprendizagem e ao propor, dentro de suas perspectivas e funções, um método de ensino, coloca o aluno no grau zero e o professor no grau dez. No entanto, assim como não se para de 

"aprender" a ler num momento dado (grau dez), também não há
possibilidade de se reconhecer um momento em que se começa do nada
(grau zero). Então, o que a escola faz, ao supor o grau zero, é utilizar
um conhecimento prévio, que o aluno tem, sem explicitar essa
utilização. Dessa forma esse conhecimento é, ao mesmo tempo suposto
e recusado, ou seja, desvalorizado. Isto resulta em uma relação
coercitiva do método de ensino sobre o processo de aprendizagem.
(ORLANDI, 1988, p. 39)

Chegamos aqui a um ponto que nos permite retornar ao "manifesto" com questões mais específicas. Se considerarmos que as práticas pedagógicas tradicionais funcionam, nas sociedades capitalistas do século XXI, ainda segundo o princípio do embrutecimento, da "explicação" como forma de aqueles que "detêm" um saber poderem "transmitir" esse saber para "aqueles que não o têm", isto é, se esta é uma falha que insiste e se arrasta nas práticas pedagógicas institucionais (escolares) há tanto tempo, então não poderíamos compreender o funcionamento das tecnologias em rede como um outro sentido possível para a relação dos sujeitos de linguagem com o conhecimento, assim como a versão bilíngue do Telêmaco o foi para os alunos do professor Jacotot?

Lembramos de Loyd Blankenship, o "Mentor", em outro trecho do "manifesto":

Descobri uma coisa hoje. Encontrei um computador. Espera aí, isso aqui é legal. Ele faz o que eu quero. Se ele comete um erro, é porque eu que estraguei tudo. Não porque ele não gosta de mim...

Ou se sente ameaçado por mim...

Ou pensa que eu sou um sabichão...

Ou não gosta de ensinar e não deveria estar aqui...

Assim, se na experiência pedagógica de Jacotot, seus alunos tiveram que submeter suas vontades à vontade (inusitada) de seu professor, mas subordinaram suas inteligências ao conhecimento inscrito em um livro, a experiência de aprendizagem via computador funciona de outro modo: ao submeter sua inteligência aos conhecimentos da, e na "rede", esse sujeito de linguagem subordinou a sua vontade apenas a ela mesma.

Esse movimento (do sujeito e) do sentido nos dá a oportunidade de compreender o equívoco a partir do qual a relação entre mestre e aprendiz se confunde com uma relação entre mestre e escravo, no sentido de que o mestre/professor tem, a partir de sua posição de sujeito (detentor) do conhecimento, poder sobre o saber do aprendiz.

Se a experiência pedagógica de Jacotot resultou em um belo exemplo de formação "emancipadora" pois deslocou, no processo de aprendizagem, a submissão da inteligência dos alunos em relação aos conhecimentos do professor, a experiência de aprendizagem do hacker via redes se apresenta como um caso ainda mais radical de emancipação, pois desfaz a necessidade de uma relação entre as "vontades": a vontade do aprendiz basta, por si só, para que haja aprendizagem, desde que ele possa submeter a sua inteligência a outra(s) inteligência(s) que não subordine(m) a sua como um "mestre".

Certamente, a pedagogia emancipadora de Jacotot e o processo de aprendizagem a partir do acesso às "redes" têm diferenças significativas. Porém, segundo pensamos, ambos se destacam por prescindir do ensino de um mestre explicador. Como enfatiza Rancière (1987, p. 31), os alunos de Jacotot "haviam aprendido sem mestre explicador, 
mas não sem mestre". Quanto ao sujeito que se engaja em processos de aprendizagem sozinho a partir do acesso às "redes", será que se poderia considerar que este realiza uma aprendizagem sem mestre? Pensamos que não: o sujeito autodidata tem, sim, um mestre que pode não ser visível ou assinalável, mas que certamente está inscrito na relação com os "novos conhecimentos" aos quais esse sujeito se submete via rede, enquanto aprendiz.

Um ponto interessante na reflexão de Rancière é a sua conclusão de que Jacotot de fato "ensinou" algo a seus alunos, embora não tenha "comunicado nada de sua ciência" (idem). Uma constatação intrigante, que nos levou a pensar sobre os sentidos possíveis de "ensino" em relação ao que temos observado sobre a aprendizagem.

Buscamos então a palavra "ensinar" em três dicionários bastante distintos entre si: um grande dicionário ${ }^{8}$, um dicionário escolar de bolso ${ }^{9}$ e um dicionário online ${ }^{10}$, a fim de observar diferentes sentidos possíveis para um ensino que vise à aprendizagem como um processo de libertação e não mera subordinação das inteligências; como "emancipação", e não "embrutecimento".

O dicionário com o maior número de definições foi o grande "Aurélio", seguido pelo digital Priberam e pelo dicionário escolar de bolso "Michaelis". As definições que se repetiram na consulta do verbete "ensinar" nos três dicionários foram instruir e educar. Além disso, segundo nossas observações, todos apresentam uma definição de "ensinar" que se refere especificamente ao trabalho do professor: lecionar (Aurélio), dar aulas (Aurélio e Michaelis) e dar lições (Priberam). No mais, uma surpresa que tivemos nessas consultas foi observar o sentido de castigo atribuído à palavra "ensino". No "Aurélio", "dar ensino a" aparece como castigar ou punir, ou ainda adestrar, termos que também aparecem no dicionário Priberam. Sentidos de "ensinar" que remetem a um "aprender" como processo de embrutecimento. Mas encontramos também, no Aurélio, uma definição de "ensino" que remete a uma aprendizagem emancipadora: aprender por si mesmo.

Temos aí o indício de um sentido possível para o trabalho do professor que recusar a inscrição na "ordem explicadora": criar condições para esse "aprender por si mesmo". O que, por sua vez, implica em inverter a ordem tradicional que regula a aprendizagem pelo ensino e fazer o contrário: condicionar o ensino à aprendizagem. Na prática, isso quer dizer que não adianta o professor chegar à aula com seus planos e métodos "prontos", ele deve deixar que o estudante desenvolva seus próprios métodos, e acolhê-los. Assim, o que determinou o sucesso da experiência do professor Jacotot foi a mesma coisa que falhou miseravelmente na prática da professora de Loyd Blankenship, que não somente censurou a conta feita "de cabeça" por seu aluno, como o acusou de ter "copiado".

Neste ponto, parece ser extremamente relevante o que diz Pêcheux (1983, p. 54) sobre a relação dos sujeitos com as "coisas-a-saber", que se realizaria sob a forma de "filiações identificadoras" e não "aprendizagens por interação". Essa formulação permite (re)pensar a aprendizagem como algo que se constitui em um processo de identificação do sujeito com as formações discursivas ${ }^{11}$. E possibilita também (re)pensar o

\footnotetext{
8 “Novo Dicionário da Língua Portuguesa”, de Aurélio Buarque de Holanda Ferreira (2ª ed., 1986).

${ }^{9}$ Michaelis: dicionário escolar da língua portuguesa ( $3^{\mathrm{a}}$ ed., 2009).

${ }^{10} \mathrm{http}: / / \mathrm{www}$. priberam.pt/dlpo.

11 Assim, a formulação do momento da compreensão (que pode assumir diferentes formas, desde o "Eureka" de Arquimedes até afirmações desinteressadas como o "eu entendo" de Loyd Blankenship)
} 
conhecimento não como um "objeto" a ser "adquirido", mas como processo (movimento) a ser vivido, uma possibilidade de o sujeito "se inscrever" na sociedade e na história.

Orlandi (2014, p. 152) apresenta uma reflexão interessante para a nossa discussão ao dizer que "na maior parte do tempo, temos mais informação do que necessitamos para movimentar a relação linguagem/pensamento/mundo, na produção do conhecimento". Segundo a autora, a informação circula com tamanha velocidade que se torna excessiva e "satura" os processos de significação, impedindo o movimento dos sujeitos e sentidos. Uma consequência disso, para a produção do conhecimento, é que a educação perde a sua dimensão como "formação" do sujeito enquanto cidadão e passa a funcionar como mera "capacitação" para o mercado de trabalho. Ainda conforme Orlandi (idem, p. 159-160), essas práticas de ensino que visam a uma noção de aprendizagem enquanto "capacitação" não oferecem ao sujeito, enquanto sujeito de linguagem, um conhecimento sobre a língua (institucionalizada) que lhe dê as condições para se significar politicamente na sociedade. Já as práticas de formação são as que trabalham essa "fluência" do sujeito de linguagem. Assim, segundo Orlandi (idem, p. 161), somente as práticas de formação são capazes de "produzir um aluno "não alienado"”.

Antes de continuarmos, gostaríamos de voltar rapidamente ao que Orlandi aponta sobre os efeitos do "excesso de informação" nos processos de produção do conhecimento. Se, como afirma a autora, esse excesso tem impedido o movimento dos sujeitos e sentidos, isso coloca a tecnologia digital e seus dispositivos em um lugar crucial para a viabilidade da "formação" na e pela educação e da "emancipação" na e pela aprendizagem, pois essas tecnologias criam condições para o sujeito não apenas lidar com o excesso de informação que elas mesmas produzem, mas, inclusive, aprender a encontrar formas de se valer dele a partir do que propomos chamar de "dispositivos de leitura" desenvolvidos a partir da tecnologia digital.

\section{A construção de um dispositivo de leitura}

Eu era muito frustrado com a escola. Achava que os professores não sabiam do que estavam falando, eles eram muito dominadores e controladores, as tarefas de casa eram uma farsa, e era como se fosse só uma forma de enclausurar alunos e obrigá-los a se manterem ocupados. E eu comecei a ler livros sobre a história da educação e como esse sistema educacional foi desenvolvido, e alternativas para ele e formas de as pessoas realmente aprenderem as coisas, em oposição a meros fatos regurgitados que os professores contavam, e isso meio que me levou a um caminho de questionar as coisas. Ao questionar a escola na qual eu estava, eu questionei a sociedade que construiu a escola, questionei os negócios para os quais as escolas estavam treinando as

representaria essa identificação com a formação discursiva ligada a um lugar específico no campo do saber e do conhecimento. Trata-se de pensar a aprendizagem como um processo de significação, por mais simples ou complexo que possa ser, a partir do qual o sentido se torna "evidente". Neste processo intervêm a língua, o sujeito, a situação de enunciação, a história, a ideologia, o inconsciente... 
pessoas, questionei o governo que configurou toda essa estrutura ${ }^{12}$. (SWARTZ, 2010)

Essas palavras mostram um aluno que, como L. Blankenship, não se identificava com seus professores ("dominadores e controladores"), com os métodos ("a tarefa de casa era uma farsa") e com o próprio espaço da escola ("uma forma de enclausurar alunos"). Um estudante "não-alienado", investido em um processo de aprendizagem baseado em gestos de leitura que resultaram em novas formas de significar, sobretudo, o modo como saber e conhecimento funcionam na sociedade.

A citação é de Aaron Swartz (1986-2013). De acordo com Noah, seu irmão mais novo, Aaron "aprendeu a aprender muito cedo". Seu pai, Robert Swartz, conta que o filho aprendeu a ler, sozinho, aos 3 anos de idade ${ }^{13}$. Com a mesma idade, começou a mexer em um computador e não parou mais. A mesma criança brilhante que viria a condenar seus professores como "dominadores" e a escola como uma "forma de enclausurar alunos" cresceu obcecada com os computadores e com os efeitos de sentidos da aprendizagem, e o que eles podem representar para a sociedade.

Aos doze anos de idade, Aaron criou um site chamado InfoBase, e definiu-o como "um vasto repositório do conhecimento humano". O conceito é o mesmo do Wikipédia, lançado pouco mais de três anos depois. Quando tinha entre treze e catorze anos de idade, Aaron participou da equipe que desenvolveu o $\mathrm{RSS}^{14}$, uma tecnologia que sumariza as atualizações de diferentes sites em um único canal manipulável pelo usuário. Aos quinze, participou da elaboração de uma nova ferramenta de licenciamento de uso de propriedade intelectual, especificamente designada no e para o espaço digital, o Creative Commons, que oferece opções menos restritivas do que o Copyright ("todos os direitos reservados") para a cópia e o compartilhamento das chamadas "obras criativas". Aos dezoito anos, Aaron fez parte da equipe fundadora do Reddit, site de mídia social que funciona como uma plataforma organizada para a criação de fóruns de discussão e compartilhamento de textos e imagens sobre todo e qualquer tipo de assunto. Depois, aos vinte anos de idade, fundou a Open Library, um banco de dados que tem como objetivo listar as principais informações bibliográficas de todos os livros já publicados.

A partir de meados de 2008, Aaron Swartz passou a se dedicar a projetos mais ligados a diferentes formas de ativismo. Nesse ano, ele baixou e publicou 2,7 milhões de documentos da corte federal americana que estavam armazenados em um sistema que

\footnotetext{
12 Tradução nossa. Segue o trecho em inglês. "I was very frustrated with school. I thought the teachers didn't know what they were talking about, they were very domineering and controlling, homework was kind of a sham, and it was just like all a way to pen students together and force them to do busywork. And I started reading books about the history of education and how this educational system was developed, and alternatives to it and ways that people could actually learn things as opposed to just regurgitating facts that teachers told them, and that kind of led me down this path of questioning things. Once I questioned the school I was in, I questioned the society that built the school, I questioned the businesses that schools were training people for, I questioned the government that set up this whole structure".

${ }^{13}$ Segundo o relato de R. Swartz, "um dia ele perguntou à mãe: 'o que é esse Free Family Entertainment Downtown at Highland Park?', [...], e ela disse 'do que você está falando?', e ele disse 'olha, diz aqui na geladeira', Free Family Entertainment Downtown at Highland Park”. Os relatos do irmão e do pai de Aaron e a maior parte das informações sobre sua vida e obra se encontram no documentário "Internet's own boy: the story of Aaron Swartz" (cf. referências).

14 Trata-se de uma forma "ancestral" dos mecanismos que produzem "feeds" de publicações atualizadas constantemente, como o do Facebook.
} 
cobrava 8 centavos por página por consulta. Uma vez que os documentos eram públicos, não foram prestadas queixas contra ele. Porém, sua sorte não foi a mesma quando ele escreveu um código para fazer downloads automáticos de um sistema de arquivamento de periódicos científicos norte-americanos. Flagrado por câmeras de vigilância, Swartz foi indiciado em quatro acusações diferentes. Mas seguiu trabalhando com o ativismo. Dois anos depois, o número de acusações contra ele pelos downloads dos periódicos científicos havia subido para treze. Até que, sem recursos para sustentar suas batalhas judiciais, Aaron Swartz tirou a própria vida em janeiro de 2013.

Embora não se identificasse especificamente como um hacker, foi através de um gesto parecido com as práticas de hacking que Swartz baixou as publicações científicas ${ }^{15}$. Além disso, seu ativismo alçava-o à posição de protagonista de novos movimentos sociais que se organizavam em torno da internet enquanto espaço simbólico-político ${ }^{16}$. Swartz foi indiciado pela segunda vez pelo governo dos Estados Unidos, em 2012, no mesmo dia em que dois hackers dos grupos Anonymous e LulzSec foram presos no Reino Unido ${ }^{17}$, momento chave de uma espécie de "cruzada" dos governos norte-americano e britânico contra as ações de hackers, bastante frequentes na época. Ele havia se tornado um "alvo" do Estado ao ser associado aos principais grupos de hackers de seu tempo ${ }^{18}$.

O que buscamos destacar aqui é como toda a sua atividade serviu ao propósito de facilitar o acesso e a circulação do conhecimento na sociedade: uma enciclopédia digital (InfoBase), um sistema de notificação de atualizações para publicações na internet (RSS), uma ferramenta para licenciar a circulação digital de obras autorais (Creative Commons), uma rede social de fóruns de discussão (Reddit), um registro de todos os livros publicados (Open Library). Todos esses instrumentos criam condições para se lidar com o "excesso" de informação que imobiliza sujeitos e sentidos (ORLANDI, 2014), constituindo assim, a partir da tecnologia digital, um "dispositivo de leitura" que faz frente às necessidades impostas pelo funcionamento dessa própria tecnologia. A constituição de tal dispositivo representa a possibilidade de resistência do sujeito aos efeitos de um processo discursivo que, como diz Orlandi (idem, p. 152), "satura a relação linguagem/pensamento/mundo". Uma possibilidade heurística para o sujeito de linguagem (se) significar (n)a sociedade pela tecnologia digital.

Pêcheux (1982), ao refletir sobre as diferentes tradições de leitura do arquivo, afirma que o mundo já se encontrava, no início da década de 1980, "diante de uma nova divisão do trabalho de leitura, uma verdadeira reorganização do trabalho intelectual", cujas consequências repercutiriam diretamente sobre a relação da sociedade com sua própria memória histórica (idem, p, 54). O autor apontava, já naquela época, para o fato de que os "cientistas" (matemáticos, engenheiros, etc.) se tornavam figuras centrais das discussões interdisciplinares sobre o tratamento do arquivo, enquanto os ditos "literatos" (historiadores, filósofos e "homens das letras" em geral) pareciam se isolar na e para a

\footnotetext{
${ }^{15}$ Após "camuflar" o IP de seu computador, Swartz deixou-o conectado diretamente a uma rede do MIT (Massachusetts Institute of Technology) com acesso ao banco de dados que continha os periódicos.

${ }^{16}$ Swartz teve um papel de destaque na campanha que levou ao arquivamento do projeto de lei conhecido como SOPA (Stop Online Piracy Act), que daria ao governo norte-americano meios para a censura da/na internet.

${ }^{17}$ Essa coincidência é mencionada pelo irmão de Aaron, Noah ( $c f$. "Internet's own boy", nas referências).

${ }^{18}$ Talvez um dos gestos mais radicais de Aaron Swartz tenha sido a publicação, em 2008, do texto intitulado

"Guerilla Open Access Manifesto", no qual ele defende o livre compartilhamento de arquivos digitais como um "imperativo moral". $C f$. Swartz (2008).
} 
sociedade, e alertava que era preciso enfrentar "a adversidade que ameaça historicamente a memória e o pensamento" (ibidem, p. 56). Adversidade que consistia (e ainda consiste) na predominância (ideológica) de uma discursividade lógico-matemática na organização político-administrativa do arquivo - memória institucional(izada) - sendo posta a serviço do poder dominante nas sociedades capitalistas: o capital.

Nesse sentido, a prática que chamamos de construção de um dispositivo de leitura consiste não apenas em criar mecanismos eficientes de ler o arquivo em um contexto marcado pelo excesso de informação, mas, também e sobretudo, em encontrar na "rede" um espaço de interlocução, de ter experiências compartilhadas que possam fazer circular outros sentidos para o sujeito, para o conhecimento, para a sociedade. Um espaço, enfim, que dê corpo aos sentidos de "educar" como formar, de "aprender" como emancipar-se, e de "ensinar" como aprender por si mesmo. Sentidos para a relação sujeito/conhecimento que muitas vezes não têm espaço nas escolas, mas ganham corpo a partir do modo como a tecnologia digital funciona discursivamente na sociedade, produzindo aberturas para novas formas de inscrição do sujeito nas práticas sociais.

A própria noção de dispositivo já indica que não se trata nunca de uma leitura, mas de processos complexos em que diversas leituras se atravessam no e pelo movimento do(s) sujeito(s), constituindo-o(s). Trata-se, portanto, se algo que não pode ser reduzido à mera "instrumentalização".

Os estudos de Orlandi sobre a leitura (1988) constituem referência fundamental para o conceito que aqui esboçamos e retomaremos em outros trabalhos. Por este motivo, optamos por encerrar esta parte de nossa reflexão com a seguinte citação, que bem ilustra o caminho que percorremos desde a leitura do "manifesto hacker":

\begin{abstract}
A convivência com a música, a pintura, a fotografia, o cinema, com outras formas de utilização do som e com a imagem, assim como a convivência com as linguagens artificiais poderiam nos apontar para uma inserção no universo simbólico que não é a que temos estabelecido na escola. Essas linguagens todas não são alternativas. Elas se articulam. E é essa articulação que deveria ser explorada no ensino da leitura, quando temos como objetivo trabalhar a capacidade de compreensão do aluno (ORLANDI, 1988, p. 40).
\end{abstract}

\title{
Considerações finais
}

As práticas de ensino nas escolas e as práticas de acesso às redes digitais produzem efeitos de sentidos distintos para a aprendizagem. O sujeito inscrito no lugar de aprendiz encontra no espaço das redes um lugar para praticar livremente seus gestos de leitura, enquanto nas escolas a leitura do professor se impõe como um "limite" a essa liberdade. Não consideramos que os limites não sejam necessários, mas precisamos estar atentos aos possíveis silenciamentos produzidos pelas relações de força, isto é, pelo fato de que as relações sociais são hierarquizadas, de modo que a partir de certos lugares o sujeito pode legitimar o sentido pela força da posição que ele ocupa. Como o professor frequentemente faz com o aluno. 
O modo como essas práticas se realizam no tempo e no espaço também é relevante para a compreensão de como elas significam. De um lado, as práticas de ensino escolares são fechadas no espaço e no tempo: em horário de aula, o aluno não pode sair de sua sala, não pode levantar de seu lugar, não pode fazer atividades que quer, apenas aquelas que o professor solicita, o que constitui o discurso ligado a essas práticas como um discurso "autoritário" (ORLANDI, 1983). Por sua vez, a virtualidade das redes relativiza a relação entre espaço e tempo, o que também não evita o fechamento espacial (há muitas pessoas, sobretudo hackers, que passam boa parte de suas vidas enclausurados em suas casas), mas, por outro lado, cria condições para que os gestos de leitura se realizem em novos ritmos e velocidades, com possibilidades de acesso que não cessam de se expandir através de novas conexões. Diferentemente do discurso produzido nas e pelas práticas escolares, o dinamismo e a descentralização das redes constitui uma discursividade mais próxima do "polêmico" e do "lúdico" (idem). Enfim, são condições de produção completamente diferentes em relação às possibilidades de leitura(s).

A compreensão de que o acesso às redes cria possibilidades de resistência a discursos dominantes na (re)produção social do conhecimento implica que a tecnologia (neste caso, a tecnologia digital) não pode ser considerada sem referência à linguagem, ao discurso e à ideologia, isso se quisermos pensar a relação tecnologia/conhecimento para além dos limites da pragmática. De um ponto de vista discursivo, a tecnologia digital pode funcionar, simultaneamente, a serviço do conhecimento e do desconhecimento, criando a um só tempo as condições para um renovado jornalismo independente e para as chamadas "fake news". Nesse cenário, o uso das tecnologias em rede para a aprendizagem aparece como uma importante condição para que os sujeitos possam (se) simbolizar (n)a sociedade com algum poder crítico.

É aí que as práticas de hacking podem aparecer como ferramentas de importância crucial na resistência a um controle cada vez mais incisivo do Estado. Os projetos criados por Aaron Swartz são um exemplo disso. Outro exemplo é o Wikileaks de Julian Assange (outro notório hacker).

O hacker se inscreve em uma relação particular com a sociedade a partir de um dispositivo de leitura que ele mesmo ajuda a construir via computador (ou smartphone ou qualquer outra ferramenta que permita o acesso à rede). Em sua prática, a tecnologia é condição de produção da aprendizagem enquanto processo de identificação com os diferentes campos do saber e do conhecimento. Assim, as práticas de ensino que ignoram as possibilidades metodológicas da tecnologia digital significam, para os hackers, como impedimentos para esses seus processos de identificação. O que muitos ainda consideram "problemas de comunicação". Questões que, segundo pensamos, estão fortemente ligadas ao funcionamento da linguagem e do discurso.

Na medida em que as práticas discursivas dos hackers se apresentam como formas de resistência a processos de segregação na organização da produção do conhecimento, ou, como escreve Pêcheux (1982), na "divisão social do trabalho de leitura", é importante compreendermos não apenas os discursos dos hackers, mas também o funcionamento dos "discursos sobre" que procuram reduzi-los ao imaginário do "banditismo digital". 


\section{Referências}

BLANKENSHIP, L. H2K2 (2002): The Conscience of a Hacker. YouTube, 12 set. 2012. Disponível em https://youtu.be/0tEnnvZbYek.

MENTOR, The. The conscience of a hacker. In: Phrack (online), v. 1, issue 7, Phile 3/10, 1986. Disponível em http://phrack.org/issues/7/3.html.

ORLANDI, E.P. Formação ou capacitação: duas formas de ligar sociedade e conhecimento. Em: FERREIRA, E.L.; ORLANDI, E.P. (Orgs.). Discursos sobre a inclusão. Niterói: Intertexto, 2014.

Por uma teoria discursiva da resistência do sujeito. Em: Discurso em análise: sujeito, sentido, ideologia. Campinas: Pontes, 2012.

A linguagem e seu funcionamento: as formas do discurso. $5^{\text {a }}$ ed. Campinas: Pontes, 2009.

Discurso e leitura. $8^{\text {a }}$ ed. São Paulo: Cortez, 2008.

PÊCHEUX, M. [1969] Análise automática do discurso. Em: GADET, F.; HAK, T. (Orgs.). Por uma análise automática do discurso. $4^{\mathrm{a}}$. ed. Campinas: Unicamp, 2010.

[1982] Ler o arquivo hoje. Em: ORLANDI, E.P. (Org.). Gestos de leitura. $3^{\mathrm{a}}$. ed. Campinas: Unicamp, 2010.

Semântica e discurso: uma crítica à afirmação do óbvio. $4^{\mathrm{a}}$. ed. Campinas: Unicamp, 2009.

[1983] O discurso: estrutura ou acontecimento? 5a . ed. Campinas: Pontes, 2008.

RANCIÈRE, J. O mestre ignorante: cinco lições sobre a emancipação intelectual. $3^{\mathrm{a}}$. ed. Belo Horizonte: Autêntica, 2015.

SWARTZ, A. [2010] In: Internet's own boy. The story of Aaron Swartz. Direção: Brian Knappenberger, Spectrum, 2014.

_ [2008] Guerilla Open Access Manifesto. Disponível em https://archive.org/details/GuerillaOpenAccessManifesto. 
Anexo

\section{VThe Conscience of a Hacker/V}

(by The Mentor)

Another one got caught today, it's all over the papers. "Teenager Arrested in Computer Crime Scandal", "Hacker Arrested after Bank Tampering"...

Damn kids. They're all alike.

But did you, in your three-piece psychology and 1950's technobrain, ever take a look behind the eyes of the hacker? Did you ever wonder what made him tick, what forces shaped him, what may have molded him?

I am a hacker, enter my world...

Mine is a world that begins with school... I'm smarter than most of the other kids, this crap they teach us bores me...

Damn underachiever. They're all alike.

I'm in junior high or high school. I've listened to teachers explain for the fifteenth time how to reduce a fraction. I understand it. "No, Ms. Smith, I didn't show my work. I did it in my head..."

Damn kid. Probably copied it. They're all alike.

I made a discovery today. I found a computer. Wait a second, this is cool. It does what I want it to. If it makes a mistake, it's because I screwed it up. Not because it doesn't like me...

Or feels threatened by me...

Or thinks I'm a smart ass...

Or doesn't like teaching and shouldn't be here...

Damn kid. All he does is play games. They're all alike.

And then it happened... a door opened to a world... rushing through the phone line like heroin through an addict's veins, an electronic pulse is sent out, a refuge from the day-to-day incompetencies is sought... a board is found.

"This is it... this is where I belong..."

I know everyone here... even if I've never met them, never talked to them, may never hear from them again... I know you all...

Damn kid. Tying up the phone line again. They're all alike...

You bet your ass we're all alike... we've been spoon-fed baby food at school when we hungered for steak... the bits of meat that you did let slip through were pre-chewed and tasteless. We've been dominated by sadists, or ignored by the apathetic. The few that had something to teach found us willing pupils, but those few are like drops of water in the desert.

This is our world now... the world of the electron and the switch, the beauty of the baud. We make use of a service already existing without paying for what could be dirtcheap if it wasn't run by profiteering gluttons, and you call us criminals. We explore... and you call us criminals. We seek after knowledge... and you call us criminals. We 
exist without skin color, without nationality, without religious bias... and you call us criminals. You build atomic bombs, you wage wars, you murder, cheat, and lie to us and try to make us believe it's for our own good, yet we're the criminals.

Yes, I am a criminal. My crime is that of curiosity. My crime is that of judging people by what they say and think, not what they look like. My crime is that of outsmarting you, something that you will never forgive me for.

I am a hacker, and this is my manifesto. You may stop this individual, but you can't stop us all... after all, we're all alike.

Artigo recebido em: julho de 2017.

Aprovado e revisado em: outubro de 2017.

Publicado em: novembro de 2017.

\section{Para citar este texto:}

KERN, Allan Strottmann. Linguagem, tecnologia e aprendizagem: a prática discursiva do hacker. Entremeios [Revista de Estudos do Discurso, on-line, www.entremeios.inf.br], Seção Temática [Linguagem e Tecnologia], Programa de PósGraduação em Ciências da Linguagem (PPGCL), Universidade do Vale do Sapucaí (UNIVÁS), Pouso Alegre (MG), vol. 15, p. 319-335, jul. - dez. 2017.

DOI: http://dx.doi.org/10.20337/ISSN2179-3514revistaENTREMEIOSvol15pagina319a335 